\title{
Competing Sorption of Se(IV) and Se(VI) on Schwertmannite
}

\author{
Bouchra Marouane ${ }^{1, *}$, Ning Chen ${ }^{2}$, Martin Obst ${ }^{3}$ and Stefan Peiffer ${ }^{1}(\mathbb{C}$ \\ 1 Department of Hydrology, University of Bayreuth, BayCEER, Universitaetsstr.30, 95440 Bayreuth, Germany; \\ s.peiffer@uni-bayreuth.de \\ 2 Canadian Light Source, Saskatoon, SK S7N 2V3, Canada; Ning.Chen@lightsource.ca \\ 3 Experimental Biogeochemistry, BayCEER, University of Bayreuth, Dr.-Hans-Frisch-Str. 1-3, \\ 95448 Bayreuth, Germany; Martin.Obst@uni-bayreuth.de \\ * Correspondence: bouchra.marouane@uni-bayreuth.de
}

Citation: Marouane, B.; Chen, N.; Obst, M.; Peiffer, S. Competing Sorption of Se(IV) and Se(VI) on Schwertmannite. Minerals 2021, 11, 764. https://doi.org/10.3390/ $\min 11070764$

Academic Editors: Sergey Churakov and Fulvio Di Lorenzo

Received: 14 June 2021

Accepted: 12 July 2021

Published: 15 July 2021

Publisher's Note: MDPI stays neutral with regard to jurisdictional claims in published maps and institutional affiliations.

Copyright: (c) 2021 by the authors. Licensee MDPI, Basel, Switzerland. This article is an open access article distributed under the terms and conditions of the Creative Commons Attribution (CC BY) license (https:// creativecommons.org/licenses/by/ $4.0 /)$.

\begin{abstract}
Schwertmannite (SHM) is a naturally occurring mineral that has been shown to effectively scavenge oxyanions from contaminated water. In this study, Fourier-transform infrared spectroscopy and X-ray absorption spectroscopy techniques in combination with wet-chemical techniques were used to study the competitive sorption of Se(IV) and Se(VI) at pH 3. The experiments were conducted with three types of schwertmannite obtained from oxidative synthesis, biogenic synthesis and highpressure compaction at different initial Se concentrations and mixing ratios for $48 \mathrm{~h}$ and 56 days, respectively. A threshold value for the uptake mechanisms was identified, which reflects the amount of easily exchangeable sulphate $(\sim 0.5 \mathrm{mmol} / \mathrm{g})$. At adsorbate concentrations below this threshold, an inner-sphere corner-sharing bidentate binuclear complex forms upon exchange with sulphate. At higher concentrations, both oxyanions become bound to SHM through co-occurrence of mainly inner-sphere and partly outer-sphere corner-sharing bidentate binuclear complexes with Fe(III) containing surface sites. Single species experiments clearly indicate a higher affinity of SHM for Se(IV). However, in mixed species experiments, competitive sorption occurs with equal or even preferential uptake of $\mathrm{Se}(\mathrm{VI})$ at concentrations much lower than the threshold value, presumably due to geometrical similarity between selenate and sulphate, and increasing preference for Se(IV) at high Se concentrations.
\end{abstract}

Keywords: schwertmannite; selenite; selenate; adsorption mechanism; XAS

\section{Introduction}

Selenium (Se) is an essential micronutrient for humans and animals. Se exists in different forms but the predominant ones are the oxyanionic species selenite (Se(IV), $\mathrm{SeO}_{3}{ }^{2-}$ ) and selenate ( $\mathrm{Se}(\mathrm{VI}), \mathrm{SeO}_{4}{ }^{2-}$ ), which are among the list of oxyanions that cause severe contamination of natural waters and aquatic environments due to their toxicity, bioavailability and mobility [1]. The occurrence of these species is typically controlled by $\mathrm{pH}$ and redox conditions with alkaline and well oxidized environments favouring the predominance of Se(VI) [2]. In contrast, Se(IV) tends to occur in moderately oxidizing and neutral $\mathrm{pH}$ environments [2]. However, both oxyanions have also been found to coexist, e.g., in industrial mining wastewater [3]. Selenium (Se) pollution and its control has thus gained increased attention and a variety of physical, chemical and biological technologies to remove Se from water have been investigated, such as nanofiltration, reverse osmosis, algae treatment and adsorption [4].

Recent experiments with granulated schwertmannite (SHM) [5], a ferric hydroxosulphate mineral (chemical formula $\mathrm{Fe}_{8} \mathrm{O}_{8}(\mathrm{OH})_{8-2 x}\left(\mathrm{SO}_{4}\right)_{\mathrm{x}}$ with $\left.1 \leq \mathrm{x} \leq 1.75\right)$ ) that typically forms under oxic, acidic ( $\mathrm{pH}$ 2.5-4.5) $\mathrm{SO}_{4}{ }^{2-}$ and Fe-rich conditions, have demonstrated a large uptake capacity of this mineral of up to $150 \mu \mathrm{mol} \mathrm{Se(IV)/g} \mathrm{SHM} \mathrm{at} \mathrm{pH} \mathrm{3.} \mathrm{SHM}$ has proven to be extremely efficient in the removal of dissolved oxyanions [6-10] such as $\mathrm{AsO}_{3}{ }^{3-}, \mathrm{AsO}_{4}{ }^{3-}, \mathrm{CrO}_{4}{ }^{2-}, \mathrm{MoO}_{4}{ }^{2-}$ or $\mathrm{PO}_{4}{ }^{3-}$. 
Hitherto, studies on uptake of Se oxyanions have focussed on ferric (oxyhydro)xides [11-18], whilst mechanistic studies about the interaction between Se oxyanions and SHM are scarce. Waychunas et al. [19] have demonstrated that Se(VI) can either directly substitute sulphate within structural tunnels of SHM or it will sorb onto the outer surfaces of the crystallites. No change of the basic structure of SHM was observed upon $\mathrm{Se}(\mathrm{VI})$ substitution. Khampila et al. [20] have investigated the adsorption of different oxyanions including $\mathrm{Se}(\mathrm{VI})$ onto SHM. Based on Zeta potential observations, they conclude that Se(VI)-like sulphate forms an outer-sphere complex, whereas the other oxyanions (phosphate, arsenate and chromate) form an inner-sphere complex. Marouane et al. [5] have investigated the adsorption of Se(IV) on granulated SHM. They observed a two-step kinetic adsorption which they attributed to fast ligand exchange with surface bound sulphate and slower intraparticule diffusion and/or exchange with structural sulphate. Yet, the mechanisms of adsorption at the various sorption sites in SHM remains unclear and in particular, the dependence of the uptake mechanism of Se oxyanions on concentration is an open question.

Hitherto, studies on adsorption of Se oxyanions by ferric (oxyhydr)oxides have been focused on the uptake of single species, i.e., either Se(IV) or Se(VI). Since wastewater and mining drainage may contain substantial amounts of both oxyanions $[4,21,22]$, the study of simultaneous sorption of $\mathrm{Se}(\mathrm{IV})$ and $\mathrm{Se}(\mathrm{VI})$ is crucial in regard to the competitiveness of the two species for adsorption sites. In this study, we therefore aim to examine the effect of the loading concentration of $\mathrm{Se}(\mathrm{IV})$ and $\mathrm{Se}(\mathrm{VI})$ as well as their mixing ratio on partitioning of these species into SHM using Se K-edge X-ray absorption spectroscopy near edge structure (XANES) and extended X-ray absorption fine structure (EXAFS). In order to study the effect of ageing on partitioning, we have performed sorption studies after various reaction times up to 56 days.

\section{Materials and Methods}

\subsection{Schwertmannite Samples}

Three different SHM specimens were used in the current study. SorbB was generated by microbial oxidation of $\mathrm{Fe}(\mathrm{II})$ in a mine water Fe removal plant operated at $\mathrm{pH}$ 2.9-3.2 [23] which we refer to as biogenic sorbent. SorbP was manufactured by high-pressure compaction of SorbB in a briquette press with controllable pressure gradient (GEOS, Freiberg, Germany) and subsequent granulation to a grain size of $0.63-2 \mathrm{~mm}$. Prior to use, both SorbP and SorbB were washed 3 times with dilute $\mathrm{HNO}_{3}$ solution at $\mathrm{pH} 3$ and dried in an oven at $50{ }^{\circ} \mathrm{C}$. The third SHM specimen SorbS was oxidatively synthesized as described by Regenspurg and Peiffer [6]. In brief, $10 \mathrm{~g}$ of $\mathrm{FeSO}_{4} \cdot 7 \mathrm{H}_{2} \mathrm{O}$ were dissolved in $1 \mathrm{~L}$ deionised water to which $\sim 5 \mathrm{~mL}$ of $32 \% \mathrm{H}_{2} \mathrm{O}_{2}$ was added dropwise to accelerate the oxidation of $\mathrm{Fe}^{2+}$ to $\mathrm{Fe}^{3+}$. The solution was stirred at room temperature for $24 \mathrm{~h}$ and the $\mathrm{pH}$ remained stable at 2.4. The precipitated orange coloured solids were filtered and oven dried for 1 day at $35-40{ }^{\circ} \mathrm{C}$.

\subsection{XRD, FTIR, BET and SEM Analyses}

$X$-ray diffraction (XRD) was carried out for the three SHM specimens before and after sorption experiments after being grounded using Co K radiation (D5000, SIEMENS; Germany). Diffractograms were evaluated using the DIFFRAC-plus evaluation software package (Bruker AXS, Germany). Fourier transformed infrared spectra of the samples were obtained using a Vektor22 Bruker and evaluated using OPUS-NT software.

Surface morphology was studied using scanning electron microscopy (SEM). The specific surface area (SSA) was determined by the five point $\mathrm{N}_{2}$ point adsorption isotherm (BET) method (Gemini 2375 v 5.01).

\subsection{Selenium Sorption to Different Schwertmannites}

Adsorption of Se species was studied at different initial Se concentrations $(0.0012,0.12$, 0.66 and $1.2 \mathrm{mM}$ ). The initial Se concentrations were selected to cover a range below at, or above the sorption capacity of approximatively $0.15 \mathrm{mmol} / \mathrm{g}$ achieved within $48 \mathrm{~h}$ for Se(IV) 
and after more than $140 \mathrm{~h}$ for Se(VI) determined in an earlier study [5]. This value reflects extrapolation of Se Freundlich isotherms (Figure S1 and Table S1 in the Supplementary Materials), and is also in accordance with the values determined for arsenite [7] and reflected a maximum solid phase loading of $0.0012,0.12$ and $1.2 \mathrm{mmol} / \mathrm{g}$ for single-species experiments and $0.0012,0.12,0.66$ and $1.2 \mathrm{mmol} / \mathrm{g}$ for mixed-species experiments.

The Se stock solution was prepared by dissolving sodium selenite $\left(\mathrm{Na}_{2} \mathrm{SeO}_{3}\right)$ and sodium selenate $\left(\mathrm{Na}_{2} \mathrm{SeO}_{4}\right)$ in deionised water (Milli-Q) to have Se(IV) and $\mathrm{Se}(\mathrm{VI})$ solution, respectively. Solutions containing Se were freshly prepared by diluting the Se stock solution with Milli-Q. Adsorption of Se(IV) and Se(VI) was studied in experiments with only one species present (single-species experiment) and in mixtures of both $\mathrm{Se}(\mathrm{IV})$ and $\mathrm{Se}(\mathrm{VI})$ at ratios of 1:1, 10:1 and 1:10 for SorbS and a ratio of 1:1 for SorbP and SorbB (mixedspecies experiment). Experiments were started by suspending $1 \mathrm{~g}$ of SHM in $1 \mathrm{~L}$ of $0.01 \mathrm{M}$ $\mathrm{KNO}_{3}$ and allowing for equilibration at $\mathrm{pH} 3 \pm 0.5$ for $24 \mathrm{~h}$ at $22 \pm 2{ }^{\circ} \mathrm{C}$ on a rotary shaker $(150 \mathrm{rpm})$ followed by addition of either Se(IV) or Se(VI) or the corresponding mixture of Se(IV) and Se(VI). Reaction times were $48 \mathrm{~h}$ to allow for fast equilibration reactions (e.g., ligand exchange [5]) step and $56 \mathrm{~d}$ to test the effect of slower reactions, such as intraparticle diffusion or exchange with structural sulphate [5]. The experimental conditions are summarised in Table 1.

Table 1. Experimental conditions for XAS analysis.

\begin{tabular}{|c|c|c|c|c|}
\hline & $\begin{array}{c}\mathrm{Se}(\mathrm{IV}) \\
\mathrm{mM}\end{array}$ & $\begin{array}{c}\mathrm{Se}(\mathrm{VI}) \\
\mathrm{mM}\end{array}$ & $\begin{array}{c}\mathrm{Se}(\mathrm{IV})+\mathrm{Se}(\mathrm{VI}) \\
\mathrm{mM}\end{array}$ & Reaction Time \\
\hline SorbS & $\begin{array}{c}0.12 \\
1.2\end{array}$ & $\begin{array}{c}0.12 \\
1.2\end{array}$ & $\begin{array}{c}0.06+0.06 \\
0.6+0.6 \\
0.6+0.06 \\
0.06+0.6\end{array}$ & $48 \mathrm{~h}$ \\
\hline \multirow{2}{*}{ SorbP } & 0.0012 & 0.0012 & $0.0006+0.0006$ & $\begin{array}{l}48 \mathrm{~h} \\
56 \mathrm{~d}\end{array}$ \\
\hline & 0.12 & 0.12 & $0.06+0.06$ & $48 \mathrm{~h}$ \\
\hline \multirow[b]{2}{*}{ SorbB } & 0.0012 & 0.0012 & $0.0006+0.0006$ & $48 \mathrm{~h}$ \\
\hline & 0.12 & 0.12 & $0.06+0.06$ & $\begin{array}{l}48 \mathrm{~h} \\
56 \mathrm{~d}\end{array}$ \\
\hline
\end{tabular}

Following equilibration, the solid and aqueous phases were separated by vacuum filtration on porous membranes ( $0.2 \mu \mathrm{m}$, polyamide, Sartorius, Göttingen, Germany). The aqueous phase was analysed for Se(IV), Se(VI), sulphate, and Fe(tot). The solid deposited on the membranes was dried in ambient air, sealed with Kapton tape until XAS analysis. The amount of adsorbed Se was determined by difference between the initial and the aqueous Se concentrations determined after the respective reaction times.

\subsection{Determination of Aqueous Selenium Species, Sulphate and Total Dissolved Iron}

Selenite and selenate were determined by graphite furnace atomic absorption spectroscopy (AAS ZEEnit 600s, Analytik Jena AG, Jena, Germany). The analysis was only possible for single-species experiment. For mixed-species experiment, it was not possible to distinguish between Se(IV) and Se(VI) by any available analysis technique. Total iron was determined by inductively coupled plasma emission spectroscopy (ICP-OES, Perkin Elmer Optima 3200 XL). Sulphate concentrations were measured spectrophotometrically by the $\mathrm{BaCl}_{2}$-Gelatin turbidimetry method [24] at $420 \mathrm{~nm}$.

\subsection{Selenium Solid-Phase Speciation}

Selenium K-edge $(12,658 \mathrm{eV}) \mathrm{X}$-ray absorption near-edge structure (XANES) and extended X-ray absorption fine-structure spectra were collected at the Hard X-ray MicroAnalysis (HXMA) Beamline at the Canadian Light Source (Saskatoon, Canada). The XANES 
data were analysed using Artemis software. The theoretical calculation for EXAFS phases scattering and amplitudes and were performed by using the software FEFF 7.02 [25,26]. The EXAFS data reduction, Linear combination fitting and the following $\mathrm{R}$ space curve fitting were performed using Athena software [26] and WinXAS [27], respectively. Details of the Se K-edge XAS analyses are provided in the Supplementary Materials.

\section{Results}

\subsection{Characterisation of Schwertmannite Specimen}

The molar mass of SHM as derived from the mean stoichiometry of the granulated $\mathrm{SHM}\left(\mathrm{Fe}_{8} \mathrm{O}_{8} \mathrm{OH}_{5.4}\left(\mathrm{SO}_{4}\right)_{1.3}\right)$ was $792.6 \mathrm{~g} / \mathrm{mol}$ with a mass fraction of $14.8 \%$ or $1.6 \mathrm{mmol}$ $\mathrm{SO}_{4}{ }^{2-}$ per $\mathrm{g}$ SHM. The X-ray diffractograms (Figure 1a) indicate poor crystallisation of the three specimen with a broad peak at $2 \theta$ of $\sim 42^{\circ}$ characteristic of schwertmannite [28]. The XRD patterns of the different SHM specimen were slightly different depending on the synthesis pathway. Peaks characteristic of goethite (20,25, 45 and 65 degrees) were identified in traces in all specimen and were relatively prominent in SorbP presumably due to some ageing during the granulation process. The XRD patterns of the samples after either $48 \mathrm{~h}$ or $56 \mathrm{~d}$ showed that the initial mineral phase was maintained during the sorption experiments (Figure S2 in the Supplementary Materials). A slight difference in specific surface area (SSA) was observed among the specimens. SorbP had the largest SSA of $33.5 \mathrm{~m}^{2} / \mathrm{g}$ compared to 14.7 and $\sim 25 \mathrm{~m}^{2} / \mathrm{g}$ for SorbB and SorbS, respectively. SorbP particles consisted of flake aggregates with a length of $2400 \mathrm{~nm}$ and a width of $1800 \mathrm{~nm}$. In contrast, SorbS particles were spherical with smooth rounded surfaces and a mean diameter of 200-600 $\mathrm{nm}$ (Figure 1b).

\subsection{Interaction between Se Species, Sulphur and Schwertmannites}

\subsubsection{Aqueous Phase}

There was a clear preference of all SHM specimen for adsorption of Se(IV) in singlespecies experiments (presence of either Se(IV) or Se(VI), Figure 2). In the case of SorbB and SorbP, Se(IV) was almost completely (average 97\%) adsorbed irrespective of the initial Se concentration $(0.0012$ or $0.12 \mathrm{mM})$ and reaction time ( $48 \mathrm{~h}$ or $56 \mathrm{~d})$. In contrast, the adsorbed fraction of Se(VI) achieved only values between $64 \%$ and $82 \%$ after $48 \mathrm{~h}$; the values increased after $56 \mathrm{~d}$ to $79 \%$ and $89 \%$. In the case of SorbS, the adsorbed fraction at an initial Se concentration of $0.12 \mathrm{mM}$ was slightly lower and had an average of $91 \%$ and $67 \%$ for Se(IV) and Se(VI), respectively. At an initial Se concentration of $1.2 \mathrm{mM}$, the adsorption rate of Se(IV) was still $96 \%$, while it decreased for Se(VI) to $45 \%$. The difference observed between SHM specimens in the Se sorption are probably due to the difference in synthetic methods and in SHM particle sizes.

Addition of Se led to a substantial release of $\mathrm{SO}_{4}{ }^{2-}$ (Figure $\mathrm{S} 3$ in the Supplementary Materials). At a low Se concentration (0.12 $\mathrm{mM} \mathrm{Se(IV),} \mathrm{Se(VI)} \mathrm{or} \mathrm{as} \mathrm{a} \mathrm{mixture),} \mathrm{the} \mathrm{release}$ rate was $\sim 0.46 \mathrm{mmol} \mathrm{SO}_{4}{ }^{2-} / \mathrm{g}$ which makes up $27.4 \%$ of the total $\mathrm{SO}_{4}{ }^{2-}$ content. In the absence of Se, the release rate was $0.36 \mathrm{mmol} \mathrm{SO}_{4}{ }^{2-} / \mathrm{g}$ so that approximately one mole sulphate was released per mole Se (sulphate release 1:1 line in Figure S3, Supplementary Materials). This 1:1 ratio decreased with increasing Se concentrations, despite an almost complete uptake of at least Se(IV) (Figure 2). Similar observations have been reported in previous studies with arsenate $[29,30]$ in which the ratio between sulphate and arsenate also decreased with increasing initial arsenate concentration. The authors concluded that at high concentration, sorption of arsenate would involve surface complexation reactions in which both sulphate and hydroxyl groups are involved so that the exchange ratio is less than 1 .

\subsubsection{Solid Phase}

The observations made at the aqueous phase are corroborated by FTIR measurements performed with SorbS. In the absence of Se, this specimen shows the characteristic absorption bands for SHM [31,32] due to splitting of the $v_{3}$ vibration of $\mathrm{SO}_{4}$ at $\sim 1122 \mathrm{~cm}^{-1}$ with 
two shoulder bands at $\sim 1060$ and $1180 \mathrm{~cm}^{-1}$, a $v_{4}\left(\mathrm{SO}_{4}\right)$ vibration at $611 \mathrm{~cm}^{-1}$ along with $v$-FeO stretching vibrations at $704 \mathrm{~cm}^{-1}$ and $428 \mathrm{~cm}^{-1}$ (Figure 3a). Consistent with the sulphate released into solution, we observed that with increasing Se concentration, the intensity of the $\mathrm{SO}_{4}{ }^{2-}$ band at $1122 \mathrm{~cm}^{-1}$ was decreasing and new features appeared.

(a)

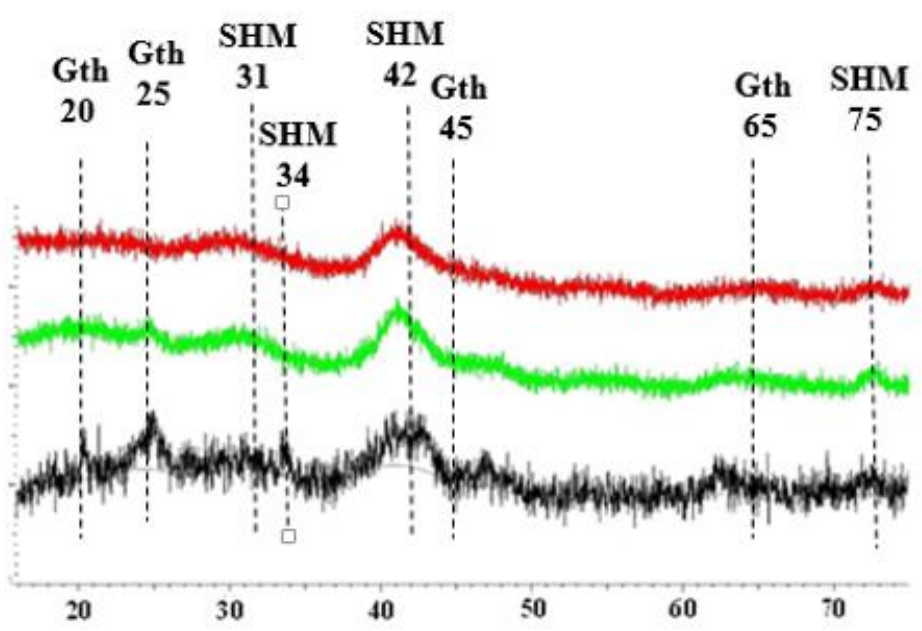

\section{Cobalt $2 \theta$}

(b)
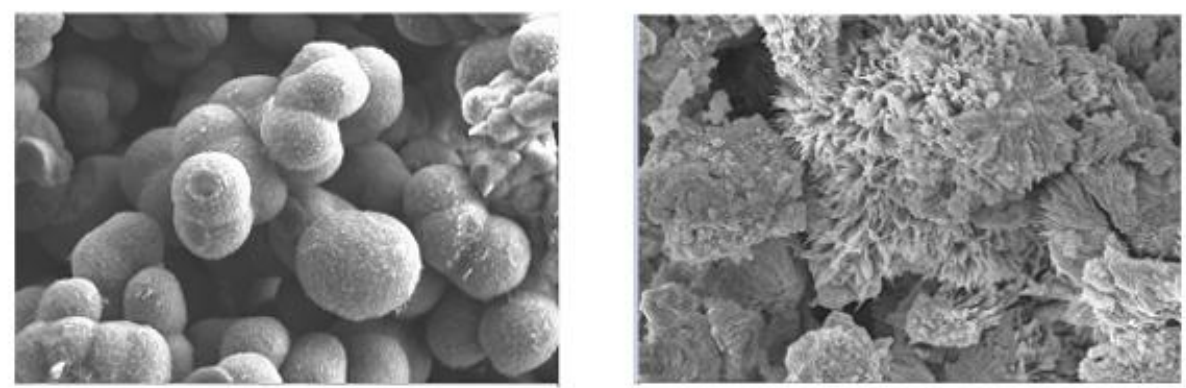

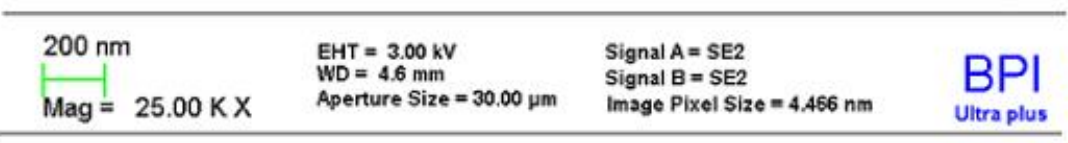

Figure 1. (a) X-Ray diffractograms of Biogenic synthesis SHM (SorbB, red), Oxidative synthesis SHM (SorbS, green) and High-pressure compaction SHM (SorbP, black); (b) SHM images for SorbS (left) and SorbP (right).
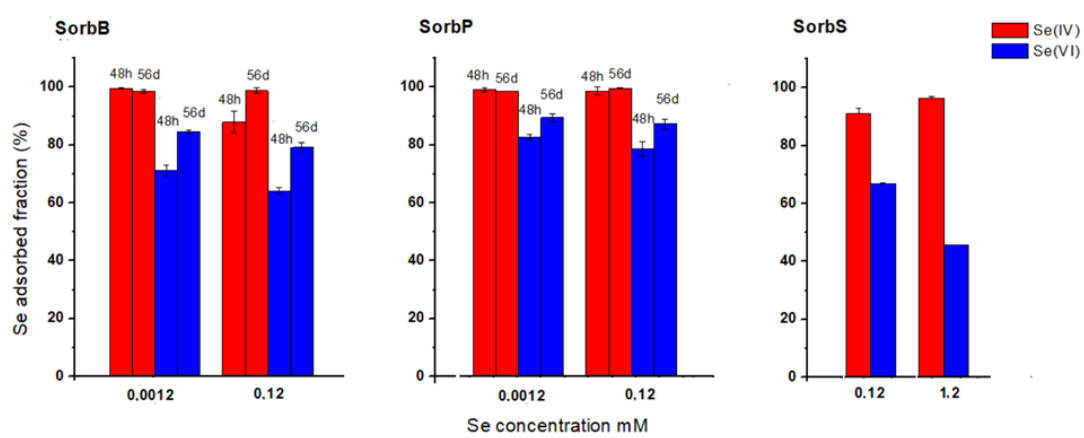

Figure 2. Fraction of adsorbed Se(IV) and Se(VI) in single-species experiments with SorbB, SorbP and SorbS $(1 \mathrm{~g} / \mathrm{L})$ as a function of initial Se concentration $(0.0012,0.12$ and $1.2 \mathrm{mM})$ and reaction time (48 h and $56 \mathrm{~d}$ ) at $\mathrm{pH}$. Experiments with SorbS lasted only $48 \mathrm{~h}$. 
(a)

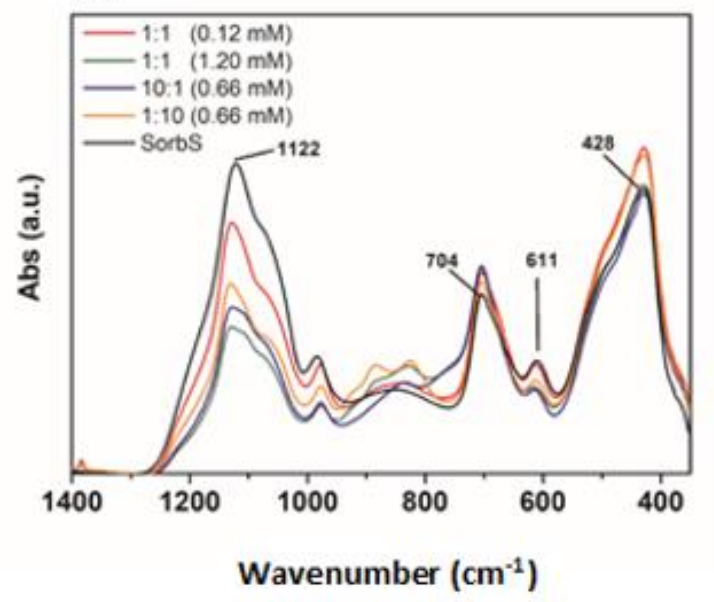

(b)

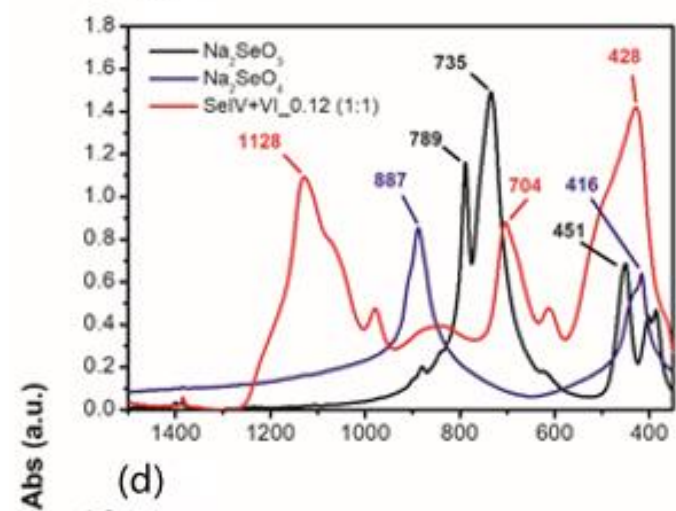

(c)

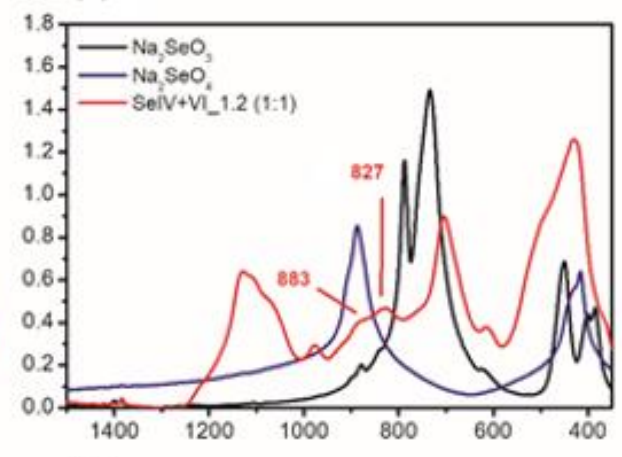

(e)

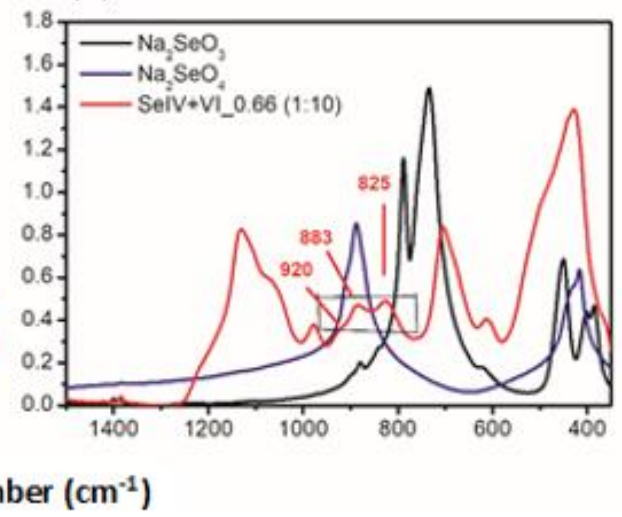

Figure 3. FTIR-spectra of (a) adsorbed Se(IV) and Se(VI) onto SorbS in mixed-species experiment at different ratio and SorbS as reference. $($ b) ratio 1:1 $(0.12 \mathrm{mM}),(\mathbf{c})$ ratio 1:1 $(1.2 \mathrm{mM}),(\mathbf{d})$ ratio 10:1 $(0.66 \mathrm{mM})$ with dominance of Se(IV) and (e) ratio 1:10 (0.66 mM) with dominance of Se(VI). Spectra of $\mathrm{Na}_{2} \mathrm{SeO}_{3}$ and $\mathrm{Na}_{2} \mathrm{SeO}_{4}$ salts $(\mathrm{c}=0.011 \mathrm{mM}$ and $\mathrm{c}=0.010 \mathrm{mM}$, respectively) are plotted as reference.

A gradual appearance of a triple splitting can be observed between 800 and $920 \mathrm{~cm}^{-1}$ (Figure $3 \mathrm{~b}-\mathrm{e}$ ), particularly when both Se oxyanions are equimolar at high concentration (Figure 3c, $\sim 827$ and $883 \mathrm{~cm}^{-1}$ ) and when Se(VI) is the dominant species (Figure 3e, $\sim 825$, 883 and $920 \mathrm{~cm}^{-1}$ ). Similarly, Su and Suarez [33] observed triplet splitting of the $v_{3}$ band at 824,891 and $916 \mathrm{~cm}^{-1}$ when increasing amounts of Se(VI) adsorbed onto amorphous iron oxide which they attributed to the formation of a bidentate bridging complex of $\mathrm{Se}(\mathrm{VI})$ at the surface. In contrast, when both Se oxyanions are equimolar at high concentration or when Se(IV) is the dominant species (Figure 3c,d), a new vibration signal appeared at $\sim 750 \mathrm{~cm}^{-1}$ which can be attributed to the $v_{3}$ vibration of selenite $[33,34]$. 
Overall, these observations imply that with increasing Se concentrations, a change in bonding of the Se species to SHM occurs. In the absence of Se, a fraction of easily exchangeable $\mathrm{SO}_{4}{ }^{2-}$ is released into the solution which is regarded to be bound to schwertmannite as a bidentate binuclear inner-sphere complex [35]. At low Se concentrations, Se oxyanions exchange with sulphate in a 1:1 ratio thereby also forming an inner-sphere complex, presumably of the same type. With increasing concentration of Se, not only the exchange ratio decreases but also new features appear in the FTIR spectra. It is obvious that low Se concentrations will not produce detectable FTIR signals. We therefore conclude that the appearance of FTIR signals at higher Se concentrations reflects a mixture of a bidentate binuclear inner-sphere complex of Se with SHM and a second bonding type of Se not exchanging with sulphate in a 1:1 stoichiometry which we assume to be outer-sphere bound tunnel sulphate [35].

The critical threshold is the amount of exchangeable $\mathrm{SO}_{4}{ }^{2-}$ which can make up more than $30 \%$ of the total sulphate content of SHM [28,31,36,37], i.e., approximately $0.5 \mathrm{mmol} / \mathrm{g}$ SHM which corresponds to $0.5 \mathrm{mM}$ for our experimental condition of a SHM concentration of $1 \mathrm{~g} / \mathrm{L}$. Hence, at Se concentrations larger than this threshold, exchange with tunnel sulphate may also be expected for both oxyanions Se(IV) and Se(VI) and the subsequent formation of a new bonding type.

\subsection{XANES and EXAFS Analyses \\ 3.3.1. Single Species}

The Se XANES spectra were identical for all SHM specimen and matched the energy position of the absorption edge of the standard $\mathrm{Na}_{2} \mathrm{SeO}_{3}$ for $\mathrm{Se}(\mathrm{IV})$ and to $\mathrm{Na}_{2} \mathrm{SeO}_{4}$ for $\mathrm{Se}(\mathrm{VI})$, irrespective of the specimen and reaction time (Figure S4 in the Supplementary Materials), implying that the respective oxidation states of the Se species were unaffected during the adsorption experiments as well during the XAFS measurements. The spectra exhibited an absorption maximum at $12,662.9 \mathrm{eV}$ and 12,668.3 eV for Se(IV) and Se(VI), respectively, followed by a downward oscillation between 12,675.3 eV and 12,734.5 eV for $\mathrm{Se}(\mathrm{IV})$ and between $12,682.2 \mathrm{eV}$ and $12,738.4 \mathrm{eV}$ for Se(VI). These positions are indicative of an inner-sphere attachment for both Se(IV) and Se(VI) to the SHM surface [38]. However, at high Se concentration on sorbS, the pre-edge intensity is slightly less that the intensity observed for sorbB and sorbP, indicative of proportional changes of the inner- and outersphere complexes [34,35].

The radial structure functions (RSFs) of the Fourier transformed data of the EXAFS spectra (Figure 4 ) show one strong sinusoidal oscillation at around $1.2 \AA$, which was fit with three oxygen atoms at $1.70 \AA$ for Se(IV) and four oxygen atoms at $1.65 \AA$ for Se(VI). At around $3 \AA$, there is another broad FT peak visibly fitted corresponding to an iron shell at a $3.33 \AA$ distance $[11,39]$. The structural parameters coordination number $(\mathrm{CN})$, interatomic distance $(\mathrm{R})$ and Debye-Waller factors $\left(\sigma^{2}\right)$ obtained from the EXAFS spectra are shown in Table 2. The Se-O distances ranged between 1.68-1.70 $\AA$ for Se(IV) and 1.65-1.67 $\AA$ for $\mathrm{Se}(\mathrm{VI})$. These observations are in good agreement with previous EXAFS studies on Se(IV) and $\mathrm{Se}(\mathrm{VI})$ adsorption on ferric (oxyhydr)oxides which revealed Se-O bond distances of 1.68-1.72 $\AA$ for aqueous and adsorbed Se(IV) $[39,40]$ and of $1.64-1.66 \AA$ for aqueous and adsorbed Se(VI) [11,15,41].

\subsubsection{Mixed Species}

Competitive sorption did not alter the valence state of both $\mathrm{Se}(\mathrm{IV})$ and $\mathrm{Se}(\mathrm{VI})$ as indicated by the unchanged position of the absorption edges. Se K-edge XANES spectra display more or less similar white line (WL) intensity of $\mathrm{Se}(\mathrm{VI})$ and of $\mathrm{Se}(\mathrm{VI})$ at all equimolar total Se concentrations after $48 \mathrm{~h}$ for all SHM specimen (Figure 5). When one species was added in excess over the other in experiments with SorbS, the WL intensity of the highconcentration species clearly became predominant (Figure 6).

EXAFS spectra for the three SHM specimens are similar to the spectra obtained from the single-species experiments with two shells presenting $\mathrm{Se}-\mathrm{O}$ and $\mathrm{Se}-\mathrm{Fe}$ bonding 
(Figures S5 and S6 in the Supplementary Materials). The interatomic distance of the $\mathrm{Se}-\mathrm{O}$

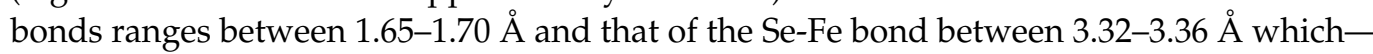
as in the single-species - can be attributed to corner-sharing bidentate-binuclear complexes for both $\mathrm{Se}(\mathrm{IV})$ and $\mathrm{Se}(\mathrm{VI})$. Similar to the single-species experiments, a decrease of $\mathrm{CN}$ for the Fe-Se bonds could be observed with increasing Se concentration, indicating the coexistence of inner and outer-sphere complexes (Table 3).
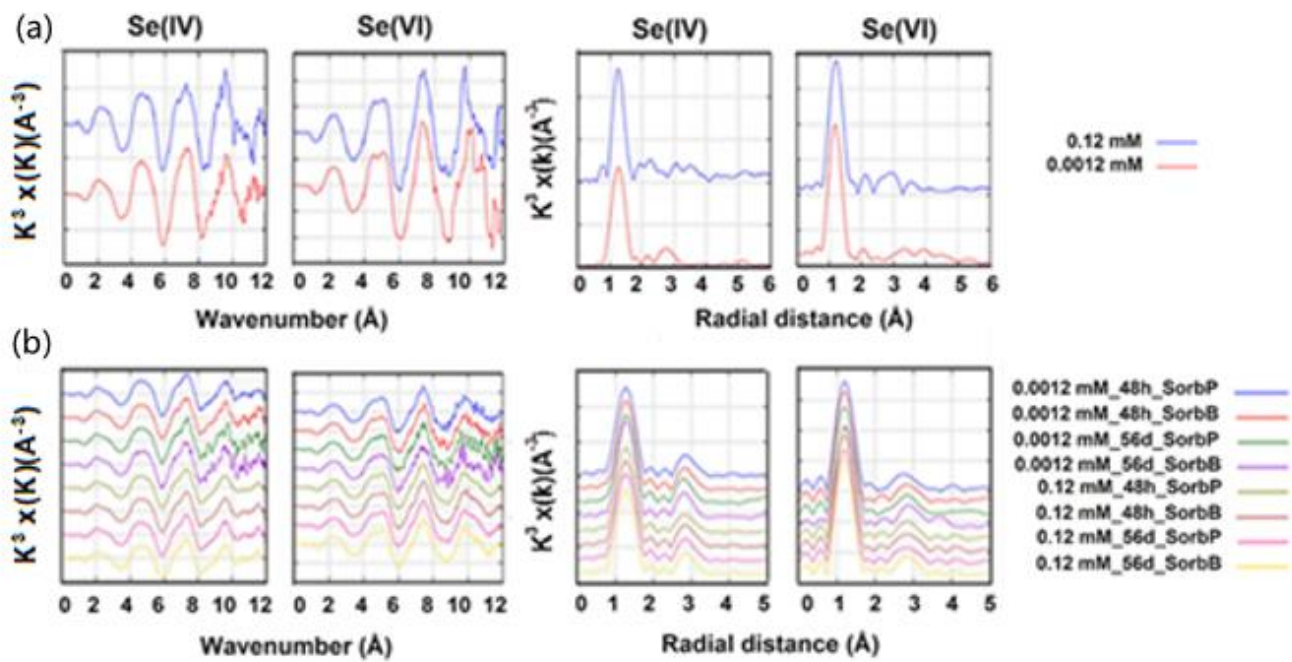

Figure 4. Normalized $\mathrm{k}_{3}$-weighted Se K-edge EXAFS spectra (left) and RSF profiles of EXAFS spectra (right) of Se(IV) and Se(VI) adsorbed onto (a) SorbS ( $1 \mathrm{~g} / \mathrm{L})$ at initial Se concentration of 0.12 and 1.2 $\mathrm{mM}$ after $48 \mathrm{~h}$, and (b) SorbB and SorbP ( $1 \mathrm{~g} / \mathrm{L})$ at initial Se concentration of 0.0012 and $0.12 \mathrm{mM}$ after $48 \mathrm{~h}$ and $56 \mathrm{~d}$ at $\mathrm{pH} 3$.

Table 2. Structural parameters of Se(IV) and Se(VI) adsorbed on SorbB, SorbP and SorbS from single-species experiments at initial Se concentrations of $0.0012,0.12$ and $1.2 \mathrm{mM}$ after $48 \mathrm{~h}$ and $56 \mathrm{~d}$ derived from EXAFS spectrum fitting.

\begin{tabular}{|c|c|c|c|c|c|c|c|c|c|c|c|}
\hline & & & \multicolumn{3}{|c|}{$\mathrm{CN}$} & \multicolumn{3}{|c|}{ R (̊̊) } & \multicolumn{3}{|c|}{$\sigma^{2}(\AA)$} \\
\hline & \multicolumn{2}{|c|}{ C of Se Species (mM) } & 0.0012 & 0.12 & 1.2 & 0.0012 & 0.12 & 1.2 & 0.0012 & 0.12 & 1.2 \\
\hline \multirow{12}{*}{$48 \mathrm{~h}$} & SorbB & \multirow{3}{*}{$\mathrm{Se}(\mathrm{IV})-\mathrm{O}$} & 2.8 & 2.8 & - & 1.70 & 1.70 & - & 0.0010 & 0.0014 & - \\
\hline & SorbP & & 3.0 & 2.8 & - & 1.70 & 1.69 & - & 0.0018 & 0.0017 & - \\
\hline & SorbS & & - & 2.9 & 2.5 & - & 1.68 & 1.70 & - & 0.0016 & 0.0014 \\
\hline & SorbB & \multirow{3}{*}{$\mathrm{Se}(\mathrm{IV})-\mathrm{Fe}$} & 2.0 & 1.9 & - & 3.35 & 3.35 & - & 0.0077 & 0.0071 & - \\
\hline & SorbP & & 2.2 & 1.9 & - & 3.35 & 3.34 & - & 0.0079 & 0.0083 & - \\
\hline & SorbS & & - & 2.2 & 1.6 & - & 3.36 & 3.35 & - & 0.0083 & 0.0083 \\
\hline & SorbB & \multirow{3}{*}{$\mathrm{Se}(\mathrm{VI})-\mathrm{O}$} & 3.6 & 3.5 & - & 1.65 & 1.66 & - & 0.0015 & 0.0014 & - \\
\hline & SorbP & & 3.7 & 3.5 & - & 1.65 & 1.66 & - & 0.0015 & 0.0016 & - \\
\hline & SorbS & & - & 3.7 & 3.6 & - & 1.65 & 1.66 & - & 0.0014 & 0.0014 \\
\hline & SorbB & \multirow{3}{*}{$\mathrm{Se}(\mathrm{VI})-\mathrm{Fe}$} & 2.2 & 1.8 & - & 3.34 & 3.34 & - & 0.0060 & 0.0060 & - \\
\hline & SorbP & & 2.1 & 1.8 & - & 3.35 & 3.34 & - & 0.0060 & 0.0062 & - \\
\hline & SorbS & & - & 1.9 & 1.6 & - & 3.32 & 3.43 & - & 0.0061 & 0.0062 \\
\hline \multirow{8}{*}{$56 \mathrm{~d}$} & SorbB & \multirow{2}{*}{$\mathrm{Se}(\mathrm{IV})-\mathrm{O}$} & 2.9 & 2.8 & - & 1.69 & 1.70 & - & 0.0010 & 0.0014 & - \\
\hline & SorbP & & 2.6 & 2.8 & - & 1.70 & 1.70 & - & 0.0010 & 0.0014 & - \\
\hline & SorbB & \multirow{2}{*}{$\mathrm{Se}(\mathrm{IV})-\mathrm{Fe}$} & 2.2 & 1.8 & - & 3.34 & 3.35 & - & 0.0074 & 0.0065 & - \\
\hline & SorbP & & 2.2 & 1.8 & - & 3.35 & 3.34 & - & 0.0075 & 0.0065 & - \\
\hline & SorbB & \multirow{2}{*}{$\mathrm{Se}(\mathrm{VI})-\mathrm{O}$} & 3.5 & 3.7 & - & 1.67 & 1.65 & - & 0.0015 & 0.0014 & - \\
\hline & SorbP & & 3.5 & 3.6 & - & 1.67 & 1.65 & - & 0.0018 & 0.0014 & - \\
\hline & SorbB & \multirow{2}{*}{$\mathrm{Se}(\mathrm{VI})-\mathrm{Fe}$} & 2.0 & 1.9 & - & 3.35 & 3.33 & - & 0.0060 & 0.0060 & - \\
\hline & SorbP & & 2.0 & 1.9 & - & 3.35 & 3.33 & - & 0.0067 & 0.0070 & - \\
\hline
\end{tabular}




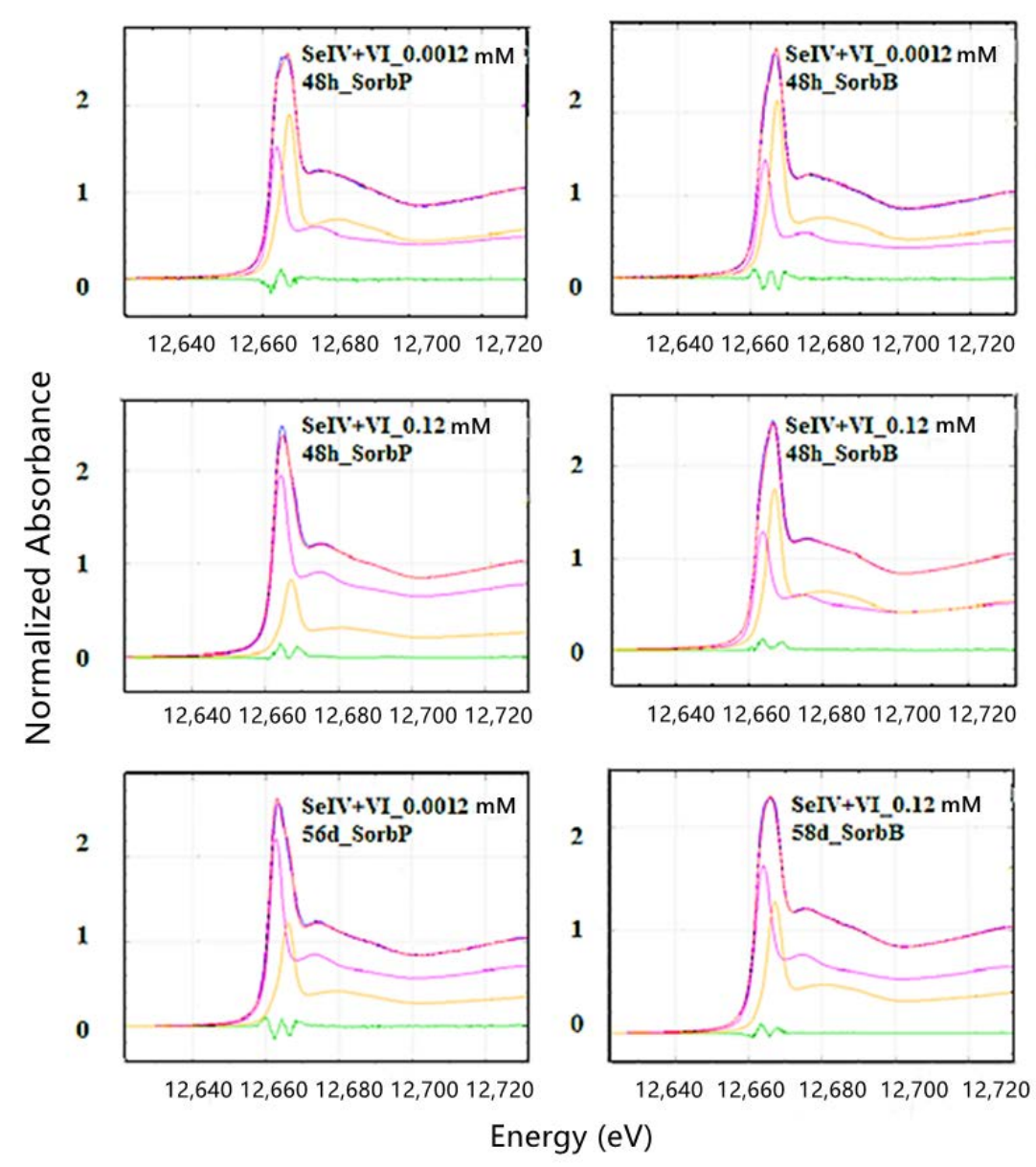

Figure 5. Se K-edge XANES results for Se(IV) and Se(VI) in mixture (ratio 1:1) adsorbed onto SorbP and SorbB $(1 \mathrm{~g} / \mathrm{L})$ after $48 \mathrm{~h}$ and $56 \mathrm{~d}$ at $\mathrm{pH} 3$.
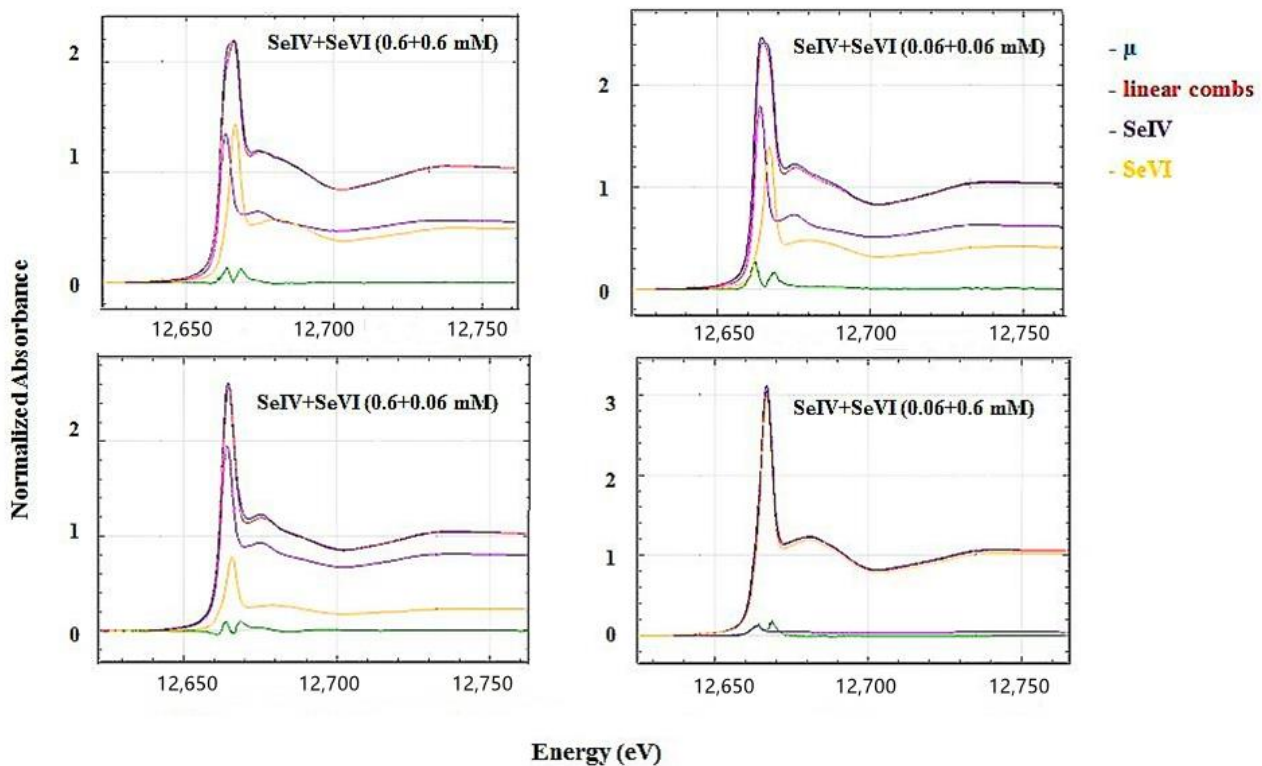

Figure 6. Se K-edge XANES results for Se(IV) and Se(VI) at different mixture ratios adsorbed onto SorbS $(1 \mathrm{~g} / \mathrm{L})$ after $48 \mathrm{~h}$ at $\mathrm{pH} 3$. 
Table 3. Structural parameters of Se(IV) and Se(VI) adsorbed on SorbB, SorbP and SorbS at initial Se concentration of 0.0012, $0.12,0.66$ and $1.2 \mathrm{mM}$ after $48 \mathrm{~h}$ derived from the EXAFS spectrum fitting.

\begin{tabular}{|c|c|c|c|c|c|c|c|c|c|c|c|}
\hline \multirow{2}{*}{\multicolumn{3}{|c|}{$\mathrm{C}$ of Se (IV) + (VI) (mM) }} & \multicolumn{3}{|c|}{ SeIV-O } & \multicolumn{3}{|c|}{ SeVI-O } & \multicolumn{3}{|c|}{ SeIV/VI-Fe } \\
\hline & & & SorbB & SorbP & SorbS & SorbB & SorbP & SorbS & SorbB & SorbP & SorbS \\
\hline \multirow{15}{*}{$48 \mathrm{~h}$} & \multirow{5}{*}{$\mathrm{CN}$} & $0.0012(1: 1)$ & 1.8 & 1.7 & - & 1.3 & 1.6 & & 1.9 & 1.9 & - \\
\hline & & $0.12(1: 1)$ & 1.5 & 2.2 & 1.9 & 1.7 & 0.8 & 1.3 & 1.8 & 1.8 & 2.3 \\
\hline & & $0.66(10: 1)$ & - & - & 2.6 & - & - & 0.4 & - & - & 2.0 \\
\hline & & $0.66(1: 10)$ & - & - & 0.4 & - & - & 3.4 & - & - & 2.0 \\
\hline & & $1.2(1: 1)$ & - & - & 1.5 & - & - & 1.3 & - & - & 1.5 \\
\hline & \multirow{5}{*}{$\mathrm{R}(\AA)$} & $0.0012(1: 1)$ & 1.70 & 1.70 & - & 1.65 & 1.65 & - & 3.35 & 3.35 & - \\
\hline & & $0.12(1: 1)$ & 1.70 & 1.69 & 1.69 & 1.66 & 1.66 & 1.66 & 3.35 & 3.34 & 3.32 \\
\hline & & $0.66(10: 1)$ & - & - & 1.69 & - & - & 1.65 & - & - & 3.34 \\
\hline & & $0.66(1: 10)$ & - & - & 1.69 & - & - & 1.65 & - & - & 3.34 \\
\hline & & $1.2(1: 1)$ & - & - & 1.69 & - & - & 1.65 & - & - & 3.36 \\
\hline & \multirow{5}{*}{$\sigma^{2}(\AA)$} & $0.0012(1: 1)$ & 0.0010 & 0.0010 & - & 0.0015 & 0.0015 & - & 0.0060 & 0.0060 & - \\
\hline & & $0.12(1: 1)$ & 0.0014 & 0.0017 & 0.0014 & 0.0014 & 0.0016 & 0.0014 & 0.0064 & 0.0071 & 0.0071 \\
\hline & & $0.66(10: 1)$ & - & - & 0.0014 & - & - & 0.0014 & - & - & 0.0071 \\
\hline & & $0.66(1: 10)$ & - & - & 0.0014 & - & - & 0.0014 & - & - & 0.0071 \\
\hline & & $1.2(1: 1)$ & - & - & 0.0014 & - & - & 0.0014 & - & - & 0.0071 \\
\hline \multirow{6}{*}{$56 \mathrm{~d}$} & \multirow{2}{*}{$\mathrm{CN}$} & $0.0012(1: 1)$ & - & 2.2 & - & - & 0.6 & - & - & 2.0 & - \\
\hline & & $0.12(1: 1)$ & 2.0 & - & - & 1.1 & - & - & 1.9 & - & - \\
\hline & \multirow{2}{*}{$\mathrm{R}(\AA)$} & $0.0012(1: 1)$ & - & 1.70 & & - & 1.67 & - & - & 3.38 & - \\
\hline & & $0.12(1: 1)$ & 1.70 & - & - & 1.65 & - & - & 3.35 & - & - \\
\hline & \multirow{2}{*}{$\sigma^{2}(\AA)$} & $0.0012(1: 1)$ & - & 0.0010 & - & - & 0.0018 & - & - & 0.0071 & - \\
\hline & & $0.12(1: 1)$ & 0.0014 & - & - & 0.0014 & - & - & 0.0065 & - & - \\
\hline
\end{tabular}

\section{Discussion}

\subsection{Binding Mechanisms of Se(IV) and Se(VI) onto Schwetmannite}

The binding mechanism appears to depend on the ferric (oxyhydr)oxide mineral. Inner-sphere bidentate-binuclear corner sharing surface complexes are assumed to occur with goethite, while bidentate mononuclear edge-sharing surface complexes of Se(IV) were observed with hematite, magnetite and maghemite [13,14,16,17]. Studies about sorption mechanisms of $\mathrm{Se}(\mathrm{VI})$ onto ferric (oxyhydr)oxides are contrasting. Se(IV) tends to form outer-sphere surface complexes with goethite [11,12,18]; however, an inner-sphere bidentate surface complex was reported for $\mathrm{Se}(\mathrm{VI})$ adsorption at the ferrihydrite and lepidocrocite surface [15].

At conditions of comparable initial Se concentrations $(0.0012$ and $0.12 \mathrm{mM})$ and reaction time ( $48 \mathrm{~h}$ and $56 \mathrm{~d}$ ), the coordination number of Se-Fe shells were 1.8-2.2 at an interatomic distance of 3.34-3.36 ̊̊ for Se(IV) and 1.8-2.2 at 3.32-3.35 $\AA$ for Se(VI); these values were almost identical for all three SHM specimens, and indicate the formation of an inner-sphere bidentate binuclear sorption complex at the surface of all the three SHM as observed with various ferric (oxyhydr)oxides [11,15,39]. However, when Se initial concentration was very high $(1.2 \mathrm{mM})$, the Se-Fe coordination number decreased to 1.6 and the interatomic distance increased to $3.43 \AA$. Wang et al. [35] reported similar small CNs (0.9-1.2) for the $\mathrm{S}-\mathrm{Fe}$ shell at similar $\mathrm{pH}$ and ascribed the values to the co-occurrence of both inner-sphere and outer-sphere complexes. Changes in the bonding mechanism with increasing concentration were also observed in experiments with chromate and arsenate [34]. At low loading $(\leq 0.4 \mathrm{mmol}$ per $\mathrm{g}$ SHM), the oxyanions preferentially formed a bidentate-binuclear inner-sphere complex at the SHM surfaces, while at high loading of $\mathrm{Cr}(\mathrm{VI})$ (4 mmol per g SHM) also outer-sphere complexes were observed. Similarly, Jordan et al. [16] studied the effect of surface loading on Se(VI) sorption at maghemite. They reported the formation of only one (monodentate) surface complex at low surface coverage, whereas the formations of two (bidentate binuclear and bidentate mononuclear) surface 
complexes were observed at higher surface coverage. Altogether, the initial concentration of Se seems to influence the mechanism of attachment of the oxyanion onto SHM.

\subsection{Competitive Effect on Partitioning of Se(IV) and Se(VI) into Schwetmannite}

Linear combination fitting (LCF) analysis revealed a clear dependence of Se uptake on initial concentrations and on time (Table 4). At low very low equimolar Se concentrations (0.0012 $\mathrm{mM})$, a slight preference for Se(VI) uptake $(47 \%$ and $52 \%$ for SorbB and SorbP, respectively) could be observed after $48 \mathrm{~h}$ which changed to $66 \%$ preference for Se(IV) after $56 \mathrm{~d}$. With higher equimolar concentrations $(0.12 \mathrm{mM})$ but still below the $0.5 \mathrm{mM}$ threshold value, the preference clearly changed even after $48 \mathrm{~h}$ to Se(IV) $(51 \%, 77 \%$, and $60 \%$ for the three SHM specimen). At excess initial equimolar concentrations (1.2 $\mathrm{mM})$, again, the preference of $\mathrm{Se}(\mathrm{IV})$ over $\mathrm{Se}(\mathrm{VI})$ with $54 \%$ to $46 \%$ could be observed.

Table 4. LCF analysis for Se(IV) and Se(VI) in mixture adsorbed on SorbB, SorbP and SorbS $(1 \mathrm{~g} / \mathrm{L})$ at initial Se concentration of $0.0012,0.12,0.66$ and $1.2 \mathrm{mM}$ at $\mathrm{pH} 3$ after $48 \mathrm{~h}$ and $56 \mathrm{~d}$.

\begin{tabular}{|c|c|c|c|c|c|c|c|}
\hline & \multirow{2}{*}{$\underset{(\mathrm{mM})}{\mathrm{C} \text { of Se (IV) }}+(\mathrm{VI})$} & \multicolumn{2}{|c|}{ SorbB } & \multicolumn{2}{|c|}{ SorbP } & \multicolumn{2}{|c|}{ SorbS } \\
\hline & & Se(IV) & $\mathrm{Se}(\mathrm{VI})$ & Se(IV) & $\mathrm{Se}(\mathrm{VI})$ & Se(IV) & $\mathrm{Se}(\mathrm{VI})$ \\
\hline \multirow{5}{*}{$48 \mathrm{~h}$} & $0.0012(1: 1)$ & 42 & 57 & 47 & 52 & - & - \\
\hline & $0.12(1: 1)$ & 51 & 49 & 77 & 23 & 60 & 40 \\
\hline & $0.66(10: 1)$ & - & - & - & - & 85 & 15 \\
\hline & $0.66(1: 10)$ & - & - & - & - & 06 & 94 \\
\hline & $1.2(1: 1)$ & - & - & - & - & 56 & 44 \\
\hline \multirow{2}{*}{$56 \mathrm{~d}$} & $0.0012(1: 1)$ & n.a & n.a & 66 & 33 & - & - \\
\hline & $0.12(1: 1)$ & 62 & 37 & n.a & n.a & - & - \\
\hline
\end{tabular}

These observations in combination with FTIR and XAS measurements suggest that at equimolar concentrations much lower than the observed threshold value, ligand exchange with inner-sphere bound sulphate is the exclusive uptake reaction. It seems to lead to a slight preferential uptake of Se(VI), presumably due to the geometric similarity between sulphate and selenate [19]. With increasing Se concentrations, also, outer-sphere tunnel sulphate becomes exchanged leading to preferential uptake of Se(IV). With increasing reaction time, this preference seems to be amplified, supporting an observation made in a kinetic study on Se uptake in which the overall uptake increased with time up to a factor of two [5].

A comparison between the three SHM shows that SorbP has a slightly higher uptake capacity which might be related to the preprocessing steps. However, no major difference could be observed between the three specimens in regard to their affinity for the Se species as well as the bonding mechanisms.

Schwertmannite has been suggested to be used as filter material for oxyanions and was successfully tested for arsenite, arsenate, selenate and selenite [5,30,42]. Hitherto, these tests were performed under conditions with only one single oxyanion being targeted. Our study, however, has clearly demonstrated that competition exists for surface sites, albeit substantially only at concentrations levels that may exceed the content of easily exchangeable sulphate of $0.0005 \mathrm{~mol} / \mathrm{g}$ SHM.

We have estimated threshold concentrations $C_{\text {threshold }}$ for the Se species at which such competitive effects may occur from their Freundlich adsorption isotherms with schwertmannite (Table S1, Supplementary Materials)

$$
\mathrm{C}_{\text {threshold }}=\left(\frac{0.0005}{\mathrm{~K}_{\mathrm{F}}}\right)^{\frac{1}{\mathrm{n}_{\mathrm{F}}}}
$$

$\mathrm{K}_{\mathrm{F}}$ : Freundlich adsorption coefficient $\left(\mathrm{L}^{\mathrm{n}} \cdot \mathrm{mol}^{(1-\mathrm{n})} / \mathrm{g}\right)$

$\mathrm{n}_{\mathrm{F}}$ : Freundlich exponent $(\leq 1)$ 
To be 0.14 and $0.46 \mathrm{mM}$ for Se(IV) and Se(VI), respectively. These values are clearly higher than the concentration of Se species typically observed in both surface and groundwater $(0.8-5000 \mathrm{nM})[43,44]$ and in mining wastewater $(0.04-150 \mu \mathrm{M})$ [45]. This calculation demonstrates that both natural and industrial water would be treatable without competitive effects. Nevertheless, the co-existence of other oxyanions such as $\mathrm{As}(\mathrm{V})$ which may occur at higher concentration (up $70 \mathrm{mM}$ ) [46] would probably decrease the removal efficiency of Se oxyanions by SHM, especially since $\mathrm{As}(\mathrm{V})$ was demonstrated to have the strongest sorption affinity among many oxyanions (e.g Se(VI), $\mathrm{Mo}(\mathrm{VI}), \mathrm{Cr}(\mathrm{VI})$ ) due to its sorption via incorporation into the SHM structure $[6,8,19,30]$. Of particular relevance is sulphate itself. In the presence of high sulphate concentration such as in natural water or in mining affected waters (3.12-32.2 mM) [47], sorption of Se oxyanions onto SHM in particular may be diminished because the affinity of the both anions for SHM is similar [41], especially at Se concentrations below the threshold concentration. Future research needs to address such competitive effects.

\section{Conclusions}

This study investigates the effect of the loading concentration of Se(IV) and Se(VI), their mixing ratio, as well as the effect of aging on partitioning of these species under acidic conditions into schwertmannite using Se K-edge XANES and EXAFS in combination with FTIR. Our results show that a threshold value for the uptake mechanism exists, which is the amount of easily exchangeable sulphate $(\sim 0.5 \mathrm{mmol} / \mathrm{g})$. At adsorbate concentrations below this threshold, an inner-sphere corner-sharing bidentate binuclear complex occurs upon exchange with sulphate. At higher concentrations, both oxyanions become bound to schwertmannite through co-occurrence of mainly inner-sphere corner-sharing bidentate binuclear and partly outer-sphere complexes with Fe(III) containing surface sites. The results are significant as they suggest that even though schwertmannite has higher affinity towards Se(IV), the competitive sorption takes place with equal or even preferential uptake of $\mathrm{Se}(\mathrm{VI})$ at concentrations much lower than the threshold value and increasing preference for Se(IV) at high Se concentrations. The present study provides novel and important insights into the competitive sorption of Se(IV) and Se(VI) on schwertmannite. Particularly, the outcomes of this study could be of high importance for development of water treatment techniques and geochemical implications.

Supplementary Materials: The following are available online at https: / www.mdpi.com/article / 10.3390/min11070764/s1, Figure S1: Freundlich isotherms of Se(IV) and Se(VI) onto schwertmannite (SorbS). Black lines represent the fitted values using the Solver tool, Figure S2: X-Ray diffractograms of SHM samples after $48 \mathrm{~h}$ and $56 \mathrm{~d}$ sorption reaction, Figure S3: Fraction of $\mathrm{SO}_{4}{ }^{2-}(\mathrm{mM})$ released from SorbS after $48 \mathrm{~h}$ at a different Se concentration in single-species and mixed-species and in control experiment. Single-species measurements were identical for both Se(IV) and Se(VI). The straight line indicates the 1:1 ratio of $\mathrm{SO}_{4}{ }^{2-}$ replacement by Se species, Figure S4: Se K-edge XANES of Se(IV) and $\mathrm{Se}(\mathrm{VI})$ adsorbed onto (a) SorbS ( $1 \mathrm{~g} / \mathrm{L})$ at Se loading concentration $(0.12$ and $1.2 \mathrm{mM})$ after $48 \mathrm{~h}$ and (b) SorbB and SorbP ( $1 \mathrm{~g} / \mathrm{L})$ at Se loading concentration $(0.0012$ and $0.12 \mathrm{mM})$ after $48 \mathrm{~h}$ and $56 \mathrm{~d}$ at pH 3 as well as $\mathrm{Na}_{2} \mathrm{SeO}_{3}$ and $\mathrm{Na}_{2} \mathrm{SeO}_{4}$ as references, Figure S5: Normalized k $\mathrm{k}_{3}$-weighted Se K-edge EXAFS spectra (left) and RSF profiles of EXAFS spectra (right) of Se(IV) and Se(VI) in mixture (ratio 1:1) adsorbed onto SorbB and SorbP ( $1 \mathrm{~g} / \mathrm{L})$ at initial Se concentration of 0.0012 and $0.12 \mathrm{mM}$ after $48 \mathrm{~h}$ and $56 \mathrm{~d}$ at $\mathrm{pH} 3$, Figure S6: Normalized $\mathrm{k}_{3}$-weighted Se K-edge EXAFS spectra (left) and RSF profiles of EXAFS spectra (right) of Se(IV) and Se(VI) in mixture at different ratios (1:1, 10:1 and 1:10) adsorbed onto SorbS $(1 \mathrm{~g} / \mathrm{L})$ at initial Se concentration of $0.12,0.66$ and $0.12 \mathrm{mM}$ after $48 \mathrm{~h}$ at $\mathrm{pH} 3$, Table S1: Freundlich isotherm parameters for Se(IV) and Se(VI) adsorption.

Author Contributions: Conceptualization, B.M. and S.P.; methodology, B.M.; software, N.C.; formal analysis, B.M. and M.O.; data curation, B.M. and N.C.; writing-original draft preparation, B.M.; writing-review and editing, B.M., N.C., M.O. and S.P.; funding acquisition, B.M. and S.P. All authors have read and agreed to the published version of the manuscript. 
Funding: This project was funded by the European Union's Horizon 2020 research and innovation programme under the Marie Skłodowska-Curie grant agreement No 706140 as well as by the grant DFG-PE 438/24-1.

Data Availability Statement: The data presented in this study are available in this article and supplementary material.

Acknowledgments: The authors thank the Canadian Light Source (CLS), Saskatoon, Canada for their support in performing Selenium K-edge XAS analyses. We thank the four anonymous referees for their thoughtful comments.

Conflicts of Interest: The authors declare no conflict of interest.

\section{References}

1. Fordyce, F.M. Selenium Deficiency and Toxicity in the Environment. In Essentials of Medical Geology: Revised Edition; Selinus, O., Ed.; Springer: Dordrecht, The Netherlands, 2013; pp. 375-416.

2. Ong, C.G.; Tanji, K.K. Evaporative concentration of trace elements in a multicell agricultural evaporation pond. J. Agric. Food Chem. 1993, 41, 1507-1510. [CrossRef]

3. Twidwell, L.; Mccloskey, J.; Miranda, P.; Gale, M. Technologies and potential technologies for removing arsenic from process and mine wastewater. In Proceedings of the REWAS'99 Global Symposium on Recycling, Waste Treatment and Clean Technology, San Sebastian, Spain, 5-9 September 1999; Volume 2.

4. Stefaniak, J.; Dutta, A.; Verbinnen, B.; Shakya, M.; Rene, E.R. Selenium removal from mining and process wastewater: A systematic review of available technologies. J. Water Supply Res. Technol. 2018, 67, 903-918. [CrossRef]

5. Marouane, B.; Klug, M.; As, S.K.; Engel, J.; Reichel, S.; Janneck, E.; Peiffer, S. The potential of granulated schwertmannite adsorbents to remove oxyanions $\left(\mathrm{SeO}_{3}{ }^{2-}, \mathrm{SeO}_{4}{ }^{2-}, \mathrm{MoO}_{4}{ }^{2-}, \mathrm{PO}_{4}{ }^{3-}, \mathrm{Sb}(\mathrm{OH})_{6}{ }^{-}\right)$from contaminated water. J. Geochem. Explor. 2020, 223, 106708. [CrossRef]

6. Regenspurg, S.; Peiffer, S. Arsenate and chromate incorporation in schwertmannite. Appl. Geochem. 2005, 20, 1226-1239. [CrossRef]

7. Paikaray, S.; Göttlicher, J.; Peiffer, S. Removal of As(III) from acidic waters using schwertmannite: Surface speciation and effect of synthesis pathway. Chem. Geol. 2011, 283, 134-142. [CrossRef]

8. Antelo, J.; Fiol, S.; Gondar, D.; López, R.; Arce, F. Comparison of arsenate, chromate and molybdate binding on schwertmannite: Surface adsorption vs anion-exchange. J. Colloid Interface Sci. 2012, 386, 338-343. [CrossRef] [PubMed]

9. Dou, X.; Mohan, D.; Pittman, C.U. Arsenate adsorption on three types of granular schwertmannite. Water Res. 2013, 47, 2938-2948. [CrossRef]

10. Janneck, E.; Burghardt, D.; Simon, E.; Peiffer, S.; Paul, M.; Koch, T. Development of an Adsorbent Comprising Schwertmannite and its Utilization in Mine Water Treatment. In Proceedings of the International Mine Water Association, Santiago de Chile, Chile, 21-24 April 2015.

11. Hayes, K.F.; Roe, A.L.; Brown, G.E.; Hodgson, K.O.; Leckie, J.O.; Parks, G.A. In Situ X-ray Absorption Study of Surface Complexes: Selenium Oxyanions on $\alpha$-FeOOH. Science 1987, 238, 783-786. [CrossRef]

12. Rietra, R.P.; Hiemstra, T.; van Riemsdijk, W. Comparison of Selenate and Sulfate Adsorption on Goethite. J. Colloid Interface Sci. 2001, 240, 384-390. [CrossRef] [PubMed]

13. Jordan, N.; Marmier, N.; Lomenech, C.; Giffaut, E.; Ehrhardt, J. Competition between selenium (IV) and silicic acid on the hematite surface. Chemosphere 2009, 75, 129-134. [CrossRef] [PubMed]

14. Kim, S.S.; Min, J.H.; Lee, J.K.; Baik, M.H.; Choi, J.W.; Shin, H.S. Effects of $\mathrm{pH}$ and anions on the sorption of selenium ions onto magnetite. J. Environ. Radioact. 2012, 104, 1-6. [CrossRef]

15. Das, S.; Hendry, J.M.; Essilfie-Dughan, J. Adsorption of selenate onto ferrihydrite, goethite, and lepidocrocite under neutral $\mathrm{pH}$ conditions. Appl. Geochem. 2013, 28, 185-193. [CrossRef]

16. Jordan, N.; Ritter, A.; Scheinost, A.C.; Weiss, S.; Schild, D.; Hübner, R. Selenium(IV) Uptake by Maghemite $\left(\gamma-\mathrm{Fe}_{2} \mathrm{O}_{3}\right)$. Environ. Sci. Technol. 2014, 48, 1665-1674. [CrossRef] [PubMed]

17. Börsig, N.; Scheinost, A.C.; Shaw, S.; Schild, D.; Neumann, T. Uptake mechanisms of selenium oxyanions during the ferrihydritehematite recrystallization. Geochim. Cosmochim. Acta 2017, 206, 236-253. [CrossRef]

18. Nie, Z.; Finck, N.; Heberling, F.; Pruessmann, T.; Liu, C.; Lützenkirchen, J. Adsorption of Selenium and Strontium on Goethite: EXAFS Study and Surface Complexation Modeling of the Ternary Systems. Environ. Sci. Technol. 2017, 51, 3751-3758. [CrossRef] [PubMed]

19. Waychunas, G.A.; Xu, N.; Fuller, C.C.; Davis, J.A.; Bigham, J.M. XAS study of $\mathrm{AsO}_{4}{ }^{3-}$ and $\mathrm{SeO}_{4}{ }^{2-}$ substituted schwertmannites. Phys. B Condens. Matter 1995, 208-209, 481-483. [CrossRef]

20. Khamphila, K.; Kodama, R.; Sato, T.; Otake, T. Adsorption and Post Adsorption Behavior of Schwertmannite with Various Oxyanions. J. Miner. Mater. Charact. Eng. 2017, 5, 90-106. [CrossRef]

21. Santos, S.; Ungureanu, G.; Boaventura, R.; Botelho, C. Science of the Total Environment Selenium contaminated waters : An overview of analytical methods, treatment options and recent advances in sorption methods. Sci. Total Environ. 2015, 521-522, 246-260. [CrossRef] 
22. Pincus, L.N.; Rudel, H.E.; Petrović, P.V.; Gupta, S.; Westerhoff, P.; Muhich, C.L.; Zimmerman, J.B. Exploring the Mechanisms of Selectivity for Environmentally Significant Oxo-Anion Removal during Water Treatment: A Review of Common Competing Oxo-Anions and Tools for Quantifying Selective Adsorption. Environ. Sci. Technol. 2020, 54, 9769-9790. [CrossRef] [PubMed]

23. Janneck, E.; Arnold, I.; Koch, T.; Meyer, J.; Burghardt, D.; Ehinger, S. Microbial synthesis of schwertmannite from lignite mine water and its utilization for removal of arsenic from mine waters and for production of iron pigments. In Proceedings of the International Mine Water Association, Sydney, NS, Canada, 5-9 September 2010.

24. Tabatabai, M.A. A Rapid Method for Determination of Sulfate in Water Samples. Environ. Lett. 1974, 7, 237-243. [CrossRef]

25. Rehr, J.J.; Albers, R.C. Theoretical approaches to x-ray absorption fine structure. Rev. Mod. Phys. 2000, 72, 621-654. [CrossRef]

26. Ravel, B.; Newville, M. ATHENA, ARTEMIS, HEPHAESTUS: Data analysis for X-ray absorption spectroscopy using IFEFFIT. J. Synchrotron Radiat. 2005, 12, 537-541. [CrossRef] [PubMed]

27. Ressler, T. WinXAS: A New Software Package not only for the Analysis of Energy-Dispersive XAS Data. J. Phys. IV Fr. 1997, 7, C2-269-C2-270. [CrossRef]

28. Paikaray, S.; Peiffer, S. Abiotic schwertmannite transformation kinetics and the role of sorbed As(III). Appl. Geochem. 2012, 27, 590-597. [CrossRef]

29. Fukushi, K.; Sato, T.; Yanase, N. Solid-Solution Reactions in As(V) Sorption by Schwertmannite. Environ. Sci. Technol. 2003, 37, 3581-3586. [CrossRef]

30. Burton, E.D.; Bush, R.T.; Johnston, S.G.; Watling, K.M.; Hocking, R.K.; Sullivan, L.A.; Parker, G.K. Sorption of Arsenic(V) and Arsenic(III) to Schwertmannite. Environ. Sci. Technol. 2009, 43, 9202-9207. [CrossRef]

31. Bigham, J.M.; Schwertmann, U.; Carlson, L.; Murad, E. A poorly crystallized oxyhydroxysulfate of iron formed by bacterial oxidation of Fe(II) in acid mine waters. Geochim. Cosmochim. Acta 1990, 54, 2743-2758. [CrossRef]

32. Cornell, R.M.; Schwertmann, U. The Iron Oxides; WILEY-VCH Verlag GmbH \& Co.KGaA: Weinheim, Germany, 2003; Volume 39, ISBN 3527302743.

33. Su, C.; Suarez, D.L. Selenate and Selenite Sorption on Iron Oxides. Soil Sci. Soc. Am. J. 2000, 64, 101-111. [CrossRef]

34. Wang, X.; Ying, H.; Zhao, W.; Feng, X.; Tan, W.; Beyer, K.A.; Huang, Q.; Liu, F.; Zhu, M. Molecular-Scale Understanding of Sulfate Exchange from Schwertmannite by Chromate Versus Arsenate. Environ. Sci. Technol. 2021, 55, 5857-5867. [CrossRef] [PubMed]

35. Wang, X.; Gu, C.; Feng, X.; Zhu, M. Sulfate Local Coordination Environment in Schwertmannite. Environ. Sci. Technol. 2015, 49, 10440-10448. [CrossRef]

36. Jönsson, J.; Persson, P.; Sjöberg, S.; Lövgren, L. Schwertmannite precipitated from acid mine drainage: Phase transformation, sulphate release and surface properties. Appl. Geochem. 2005, 20, 179-191. [CrossRef]

37. Fernandez-Martinez, A.; Timón, V.; Román-Ross, G.; Cuello, G.; Daniels, J.; Ayora, C. The structure of schwertmannite, a nanocrystalline iron oxyhydroxysulfate. Am. Mineral. AMER Miner. 2010, 95, 1312-1322. [CrossRef]

38. Chubar, N.; Gerda, V.; Szlachta, M. Mechanism of Selenite Removal by a Mixed Adsorbent Based on Fe-Mn Hydrous Oxides Studied Using X-ray Absorption Spectroscopy. Environ. Sci. Technol. 2014, 48, 13376-13383. [CrossRef] [PubMed]

39. Manceau, A.; Charlet, L. The Mechanism of Selenate Adsorption on Goethite and Hydrous Ferric Oxide. J. Colloid Interface Sci. 1994, 168, 87-93. [CrossRef]

40. Peak, D. Adsorption mechanisms of selenium oxyanions at the aluminum oxide/water interface. J. Colloid Interface Sci. 2006, 303, 337-345. [CrossRef] [PubMed]

41. Peak, D.; Sparks, D.L. Mechanisms of selenate adsorption on iron oxides and hydroxides. Environ. Sci. Technol. 2002, 36, 1460-1466. [CrossRef]

42. Song, J.; Jia, S.Y.; Ren, H.T.; Wu, S.H.; Han, X. Application of a high-surface-area schwertmannite in the removal of arsenate and arsenite. Int. J. Environ. Sci. Technol. 2015, 12, 1559-1568. [CrossRef]

43. Bailey, R.T. Review: Selenium contamination, fate, and reactive transport in groundwater in relation to human health. Hydrogeol. J. 2016, 25, 1191-1217. [CrossRef]

44. Ullah, H.; Liu, G.; Yousaf, B.; Ali, M.U.; Irshad, S.; Abbas, Q.; Ahmad, R. A comprehensive review on environmental transformation of selenium: Recent advances and research perspectives. Environ. Geochem. Health 2019, 41, 1003-1035. [CrossRef]

45. Wasewar, K.L.; Prasad, B.; Gulipalli, S. Adsorption of Selenium Using Bagasse Fly Ash. Clean Soil Air Water 2009, 37, 534-543. [CrossRef]

46. Smedley, P.L.; Kinniburgh, D.G. A review of the source, behaviour and distribution of arsenic in natural waters. Appl. Geochem. 2002, 17, 517-568. [CrossRef]

47. USEPA. Drinking Water Advisory: Consumer Acceptability Advice and Health Effects Analysis on Sulfate. EPA-822-R-03-007; USEPA: Washington, DC, USA, 2003. 